Neurosurg Focus 10 (1):Article 3, 2001, Click here to return to Table of Contents

\title{
Spinal lipomas
}

\author{
JeFFRey P. Blount, M.D., AND Scott Elton, M.D. \\ Division of Neurosurgery, University of Alabama at Birmingham, Children's Hospital of Alabama, \\ Birmingham, Alabama
}

\begin{abstract}
Lipomas of the spinal cord are among the most fascinating lesions encountered by the pediatric neurosurgeon. An understanding of spinal lipomas may, however, be difficult because the terminology used to describe the accumulations of spinal fat is confusing, inconsistently applied, and at times contradictory. An anatomical characterization of lipomas may assist in understanding these lesions. Lipomas of the spinal cord are very rare and cause symptoms related to mass effect and secondary compressive myelopathy. Lipomas of the conus medullaris (or lipomyelomeningocele) are the most common form of fatty masses in the spine and can be divided into dorsal, caudal, and transitional forms. These lesions are a manifestation of occult spinal dysraphism and a common cause of the tethered cord syndrome (TCS). The natural history of untreated lipomyelomeningocele, although incompletely understood, appears to be progressive neurological deterioration with loss of bladder control. Timely, careful surgical intervention may prevent significant neurological deterioration and progressive disability in the majority of children harboring these lesions. In surgical intervention the surgeon seeks to disrupt the connection between the fibrofatty mass and underlying cord as well as to reestablish normal anatomical planes. Several intraoperative video segments illustrating lipomyelomeningocele resection are included in this paper. Lipomas of the terminal filum (fatty filum) are truly occult and are also associated with TCS. Surgical treatment of filum lipomas carries significantly lower risk than that for lipomas of the conus medullaris. Again, the goal of surgery is to disrupt the connection between the abnormal fibrofatty tissue and the underlying spinal cord.
\end{abstract}

\section{KEY WORDS • lipoma • lipomyelomeningocele • terminal filum • occult spinal dysraphism $\bullet$ tethered cord syndrome}

Lipomas of the spinal cord are among the most fascinating lesions encountered frequently by the pediatric neurosurgeon. Timely, careful surgical intervention may prevent the development of significant neurological deterioration and progressive disability in the majority of children harboring these lesions. As such, spinal lipomas can be among the most rewarding of congenital lesions to treat. An understanding of spinal lipomas may, however, be difficult because the terminology used to describe the accumulations of spinal fat is confusing, inconsistently applied, and at times contradictory. The terms lipoma, lipomyelomeningocele, and lipomeningocele are used by different authors to describe the same or similar conditions. The term lipomyelomeningocele is misleading in that there is no anomaly of the overlying skin. The suffix "oma" implies a neoplastic event in the pathophysiology of the lesion; however, the majority of spinal lipomas arise from a disorder of embryogenesis and reflect a form of OSD. Furthermore, such lipomas do not consist of a single cell type but rather demonstrate fibrous tissue, muscle cells, neural tissue, and a variety of other cell types that arise from all three embryonic layers. ${ }^{40,47}$ Whether such

Abbreviations used in this paper: $\mathrm{CSF}=$ cerebrospinal fluid; MR = magnetic resonance; OSD = occult spinal dysraphism; TCS $=$ tethered cord syndrome disordered embryogenesis gives rise to a truly teratomatous fatty neoplasm is controversial. ${ }^{32,35}$ Other less common spinal lipomas are true benign fatty neoplasms of adipocytes that may become symptomatic by virtue of their mass. To make matters more confusing, various disorders that differ in their pathophysiology and natural history result in fat accumulation within the spine.

\section{DEFINITION OF TYPES OF SPINAL LIPOMA}

Fat accumulations within the spine can be broadly divided into five clinical entities.

\section{Lipomyelomeningocele}

Lipomyelomeningocele (or lipoma of the conus medullaris) is the most commonly fatty mass occurring along or within the spine. Lipomyelomeningocele is a form of OSD in which a subcutaneous fibrofatty mass traverses the lumbodorsal fascia, causes a spinal laminar defect, displaces the dura, and infiltrates and tethers the spinal cord..$^{49}$

\section{Fatty Filum}

Fatty filum (or lipoma of the terminal filum) is the accumulation of fat within the terminal filum and this lesion represents a less severe form of OSD. The filum is usual- 
ly thickened in and around the regions of fat deposition ( $>$ $2 \mathrm{~mm}$ as demonstrated on $\mathrm{T}_{1}$-weighted MR imaging). The fat is thought to reflect disordered development of the filum. As such, the filum becomes more robust and more constrictive of the normal ascent of the conus medullaris during normal development. Some authors refer to this as the tight filum syndrome, and it can contribute to neurological deterioration. ${ }^{45}$

\section{Intradural Spinal Lipoma}

Intradural spinal lipomas (or lipoma of the spinal cord $)^{25,57,71}$ are fatty accumulations that are completely intradural, have no subcutaneous component, and manifest symptoms when they become large enough to have mass effect. These lipomas tend to be dorsally situated in the spinal cord and may demonstrate an exophytic component. They are rare (4\% of all lipomas) and are found most commonly in the thoracic region. They are, however, found in all spinal regions and appear to be most common in the cervical region in children. Some authors have considered these spinal lipomas with dura intact (subpial). The pathophysiology of these lesions is poorly understood.

\section{Epidural Lipomatosis}

Epidural lipomatosis occurs when excessive amounts of epidural fat are synthesized. The most frequent clinical setting for this is in a patient receiving exogenous steroid agents, but it is occasionally seen in cases of severe obesity. The excessive fat exerts mass effect on the underlying neural structures and can cause a compressive myelopathy or cauda equina syndrome. Chronic lipomatosis is usually treated with weight loss or reduction or discontinuation of steroids. Rarely, an acute myelopathy or cauda equina syndrome resulting from epidural lipomatosis will require decompressive surgery.

\section{Spinal Angiolipoma}

Angiolipomas are benign fatty harmartomas consisting of abnormally differentiated vessels and adipose tissue. ${ }^{58,75}$ They are commonly found in the skin, muscle, bone, and oral cavity, but there are rare reports of their appearance in the spine or with extension to the brain. ${ }^{1}$

It is recognized that fat accumulations occur for a variety of reasons; however, the focus of this paper will be on fatty accumulations that arise as a result of a dysraphic event: lipomas of the conus medullaris (lipomyelomeningocele) and lipomas of the terminal filum (fatty filum). These are the most common spinal lipomas encountered in clinical practice and are considered here in detail. A brief consideration of subpial lipomas concludes this discussion.

\section{EPIDEMIOLOGY OF LIPOMA}

\section{Lipoma of the Conus Medullaris (Lipomyelomeningocele)}

A lipomyelomenigocele occurs in approximately one in 4000 births in the United States and females are at increased risk (prevalence female/male ratio 1.5:1). ${ }^{27,51}$ The lesions are typically diagnosed in children because of the presence of a cutaneous marker or fatty mass; however, the diagnosis of underlying spinal dysraphism is all too often missed. ${ }^{27,45}$ The proper association of a skin marker indicating an underlying problem is not made until adulthood when back pain or a progressive neurological deficit calls attention to the problem. ${ }^{38,45,49}$

\section{Fatty Filum (Lipoma of the Terminal Filum)}

The true incidence of fatty filum is unknown because the condition is truly occult. In the majority of patients there are no cutaneous anomalies or subcutaneous collections to indicate an underlying problem as is seen in cases of lipomyelomeningocele. ${ }^{45}$ Prior to the era of MR imaging there was little appreciation for this condition. In large series of lumbosacral lipomas the authors have reported that lipomas limited to the terminal filum represented 13 to $26 \%$ of lesions accounting for tethered cord.

The tight filum syndrome has been described as a cause of tethered spinal cord in which an abnormally enlarged terminal filum prevents normal ascent of the spinal cord within the lumbar spinal canal during normal development. Greater than $90 \%$ of cases in which this diagnosis is made demonstrate adipose cells in the filum. ${ }^{45}$

An enlarged fat-filled filum is commonly seen in cases of caudal regression syndrome and other anomalies of the caudal cell mass. ${ }^{51,61}$ These disorders are characteristically syndromic (vertebral, anal, tracheal, esophageal, and renal anomalies; Currarino triad) and involve cloacal and urogenital structures in addition to a tethered cord from an enlarged fat-infiltrated filum. ${ }^{2,18,21,52,67}$

The myelocystocele is a rare lesion characterized by cystic dilation of the distal end of the spinal cord. It is considered here because it is thought to arise via a disorder of secondary neurulation, which is currently the most widely supported hypothesis of the cause of the lipoma of the terminal filum. ${ }^{29}$ This lesion accounted for $5 \%$ of all spinal lipomas in the large series reported by Byrne, et al..$^{10} \mathrm{In}$ this lesion the central spinal canal demonstrates terminal cystic dilation into a meningocele.

\section{Intradural Spinal Lipoma}

These rare lesions affect males and females equally and represent only approximately $7 \%$ of spinal lipomas. In adults they are most commonly found in the thoracic region, whereas in children the cervical spine appears to be the most common site. ${ }^{48}$

\section{DIAGNOSIS OF LIPOMA OF THE CONUS MEDULLARIS}

\section{Signs and Symptoms}

Subcutaneous Fat Mass. A palpable, nontender subcutaneous mass of fat (Fig. 1) is present in greater than $90 \%$ of patients harboring a lipomyelomeningocele. In the incidence of fatty mass differs among large series of patients, but this likely reflects an age bias. In series such as those reported from Toronto and Chicago the authors report on younger patients (average age 6 months) when the finding of a large subcutaneous mass is likely to prompt referral and comprehensive evaluation. ${ }^{10,20,27,38,40,73}$ In those series in which older children are reported this finding is observed less frequently. 33,55 


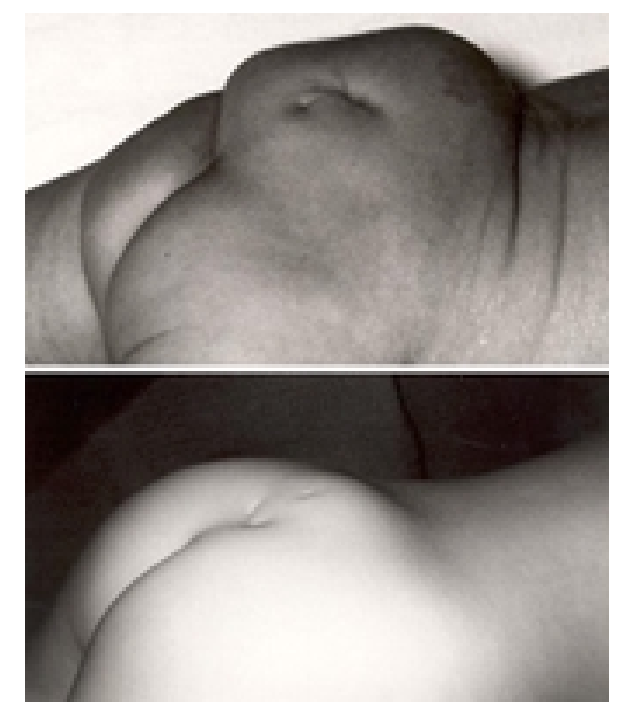

Fig. 1. Photographs showing a palpable nontender soft mass of fat, the most common finding in lipomas of the conus medullaris. These can be distinguished from coccygeal teratomas by virtue of their somewhat higher position and soft contents. Teratomas will often have a mixed density of contents and will lie lower on the buttock. Digital rectal examination also allows palpation of the teratoma between the rectum and sacrum (see Oakes). Upper: A moderate-sized lumbosacral mass with an associated dermal sinus tract and cutaneous hemangioma. Lower: A somewhat smallersized mass, also associated with dermal sinus tract and asymmetrical gluteal cleft. Adapted with permission from Oakes.

Typically this lesion is fully skin covered, nontender, and extends in the midline off the spine. Slightly more than one third of such lesions will be asymmetrical with regard to midline. ${ }^{49}$ There is a higher incidence of neurological deficit, usually greatest in the lower extremity ipsilateral to the side of the mass, in those patients with an asymmetrical mass. Normal neurological function at birth can be anticipated in the majority of infants with a symmetrical lipomyelomeningocele. ${ }^{49}$

The intergluteal crease is usually preserved in lipomyelomeningocele but may be obscured or distorted when a myelocystocele (cystic terminal dilation of the central canal into a meningocele) is present. ${ }^{29}$

Some lesions demonstrate considerable bulk, and the associated cosmetic defect is instrumental in prompting evaluation and care.

Skin Abnormalities. Abnormalities in the skin (Fig. 1) are very common $(>50 \%)$ in patients harboring a lipomyelomeningocele. These anomalies may include an area of hypertrichosis, a capillary hemangioma, a dermal sinus tract, a dimple, or an additional appendage. ${ }^{14,20}$ Many of these lesions occur in isolation and do not reflect underlying dysraphism. ${ }^{46}$ When seen in combination with other cutaneous abnormality, the detection of a cutaneous anomaly should prompt a careful search for an underlying occult dysraphic lesion. Angiomas are particularly commonly associated with subcutaneous fatty masses of lipomyelomeningocele. ${ }^{4}$ Truly isolated angiomas are, however, rarely indicative of an OSD.

The commonly seen coccygeal pit can be differentiated from a dysraphism-associated dermal sinus tract by virtue

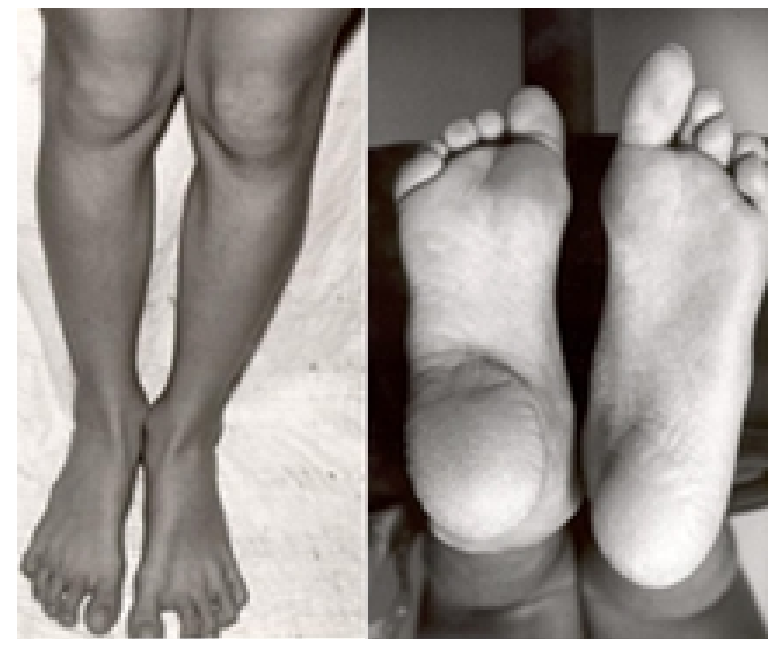

Fig. 2. Left: Progressive asymmetrical foot deformities are commonly seen in children harboring lipomas of the conus medullaris. Asymmetrical innervation of lower-extremity musculature may lead to cavovarus or carovalgus deformities and muscle wasting. Splaying of the toes or hammer toes may also be seen. Right: Asymmetry of the arch of the foot attests to asymmetrical innervation due to lipomyelomeningocele.

of its location within the gluteal cleft and the absence of other skin markers for dysraphism (including asymmetric cleft, fatty mass, hemangioma, and hypertrichosis). ${ }^{49}$

Extremity and Foot Changes. Morphological changes in the extremities and feet are present early in childhood in some children harboring lipomyelomeningoceles. ${ }^{41}$ Such changes are often progressive and, as such, are most often detected later in childhood. Asymmetrical foot deformities (typically cavovarus but occasionally cavovalgus) arise from asymmetrical innervation of the feet (Fig. 2). Foot-length and leg-length discrepancies, muscle mass discrepancies, and progressive joint deformities can be seen as well. ${ }^{49}$

\section{Neurological Changes}

Sensory/Motor Changes. Although the majority of infants born with a symmetrical lipomyelomeningocele are neurologically intact, progressive neurological deterioration is common and represents the single most important reason why detection and appropriate treatment is important. The authors of many large series have demonstrated progressive neurologic AL decline in patients with untreated lipomyelomeningocele. ${ }^{8,40,41}$ Both upper- and lowermotor neuron deficits may be seen in the same extremity. Progressive asymmetrical weakness with patchy sensory loss in the lower extremities is a common finding in these patients.

Bladder/Sphincter Changes. Deterioration of urinary bladder function is common in patients harboring lipomyelomeningocele. The detection of bladder anomalies appears to correlate with the age at which a child is examined and the sensitivity of the means by which the patient is evaluated. ${ }^{11}$ Using urodynamic studies Foster and colleagues ${ }^{23}$ found abnormal bladder function in 15 of their 19 patients older than age 18 months. By contrast in five of 12 patients younger than age 18 months bladder dys- 
function was demonstrated. In a series of 35 children with lipomyelomeningocele repair reported by Atala, et al., ${ }^{4}$ all six older children were shown to have bladder dysfunction. Recently Satar and associates ${ }^{60}$ reviewed 21 older patients in whom OSD had been diagnosed; of these 19 underwent operative release. No improvement or worsening of symptoms in 16 of the 19 patients led the authors to conclude, "Older children and adults with occult spinal dysraphism are more likely to present with irreversible urological findings than younger children." By contrast, in a different report by the same group only seven of 28 ( $<$ 1 year of age) surgically treated patients with a lipomyelomeningocele were shown to have abnormal bladder function on preoperative urodynamic studies. ${ }^{59}$

By the time children reach 3 to 4 years of age, many are seen primarily for signs of neurogenic bladder. ${ }^{49,73}$ This may be clinically manifest as repeated urinary tract infections, disordered or delayed voiding control, or frank incontinence. ${ }^{60}$ By contrast rectal incontinence is unusual.

Pain. Low-back pain or tenderness of the subcutaneous mass is very unusual in infants and children but is seen in adolescents and adults. Generalized low-back pain, radicular leg pain, which may vary in distribution with time, and Lhermitte sign have all been described. ${ }^{6,11,43,52}$ Often such pain is precipitated by physical exertion, traumatic injury, or direct contact, but spontaneous symptoms may occur as well.

\section{DIAGNOSIS OF LIPOMA OF THE TERMINAL FILUM}

\section{Signs and Symptoms}

Typically a lipoma of the terminal filum only comes to attention when clinically manifest as part of the tight filum syndrome. In this syndrome a tethered cord results from a failure of ascension of the normal conus medullaris due to constriction from the robust filum. Lipomas of the filum may remain clinically silent during childhood and become apparent during a period of rapid growth associated with adolescence. Characteristically this is first manifest as progressive low-back pain. ${ }^{11}$ Often this pain is posture related and may be worsened with stretching, vigorous physical activity, or physical contact including sports. Lipomas of the conus medullaris (lipomyelomeningocele) and lipomas of the filum induce injury to the spinal cord via a tethering mechanism. As such, it is not surprising that many characteristics of the early symptoms are identical. Similarly the progressive neurological decline associated with lipomyelomeningocele may be seen in patients with a lipoma of the terminal filum.

\section{NEURODIAGNOSTIC IMAGING}

After OSD is suspected on clinical grounds the first logical step is to obtain appropriate neuroimaging studies to define the anatomical and pathological features of the lesion. Ultrasonography is a useful modality in the radiological evaluation of an infant suspected of harboring a lipomyelomeningocele. Lipomatous tissue is highly echogenic and as such can be readily defined on an ultrasound. A combination of plain x-ray films and MR images most precisely and efficiently defines lipomas of the spine in older children and adults. Computerized tomography scanning may be reserved for cases in which additional bone abnormalities are suspected based on clinical or radiological findings (for example, diastomyelia or split cord malformation). Computerized tomography myelography provides excellent resolution of the anomaly; however, this modality is invasive, requires exposure to radiation and requires lumbar puncture which can be a particularly hazardous undertaking in the setting of a lowlying conus. ${ }^{13,62}$

Plain x-ray films almost uniformly demonstrate abnormal findings. The most common findings include dorsal midline fusion defects (spina bifida) and a widened spinal canal. In young children ( $<18$ months of age) incomplete calcification of bone elements limits the practical utility of conducting plain radiography. ${ }^{26}$

Magnetic resonance imaging has evolved to become the imaging modality of choice for dysraphic states. ${ }^{9} \mathrm{Li}-$ pomatous tissue demonstrates high signal on $\mathrm{T}_{1}$-weighted MR images and low signal on $\mathrm{T}_{2}$-weighted MR images (Fig. 3). Contrast material administration is not necessary. Precise definition of the relationship of normal and pathological structures combined with the ability to obtain images in three dimensions allows the surgeon to plan an operative approach in which understanding of the lesion is optimal. ${ }^{9,26,43}$

The greatest drawback to MR imaging is its ineffectiveness postoperatively. Characteristically the area in which the lipomyelomeningocele has been resected and the cord untethered demonstrates a diffuse area of abnormality where tissue planes are disrupted; the conus medullaris remains low; and the resulting scar tissue melds homogeneously with residual fibrofatty tissue of the lipoma. Magnetic resonance imaging does not provide meaningful information with regard to the success of an untethering operation nor can it establish retethering.?

\section{PATHOPHYSIOLOGY AND NATURAL HISTORY}

The pathophysiology of spinal lipomas can be broadly characterized into two events: those pathological events that occur during embryonal stage that give rise to the malformation and those events resulting from the lipoma that impart neurological injury to the spinal cord. These will be considered individually.

\section{EMBRYOLOGICAL DEVELOPMENT}

\section{Lipomas of the Conus Medullaris}

Details of the disordered embryological development currently considered as the best explanation for lipomas have been reported by McLone and Naidich ${ }^{44}$ and are outlined briefly here.

In normal development blastocyst formation occurs from gestational Days 1 to 4. An inner cell mass develops into discrete layers of hypoblast and epiblast. By gestational Days 13 to 16 the primitive streak forms and invaginates to give rise to the primitive groove. Formation of the notochordal process begins on or around gestational Day 16. The neuroectoderm first becomes visible by gestational Day 17 along a shallow neural groove. From gestation- 


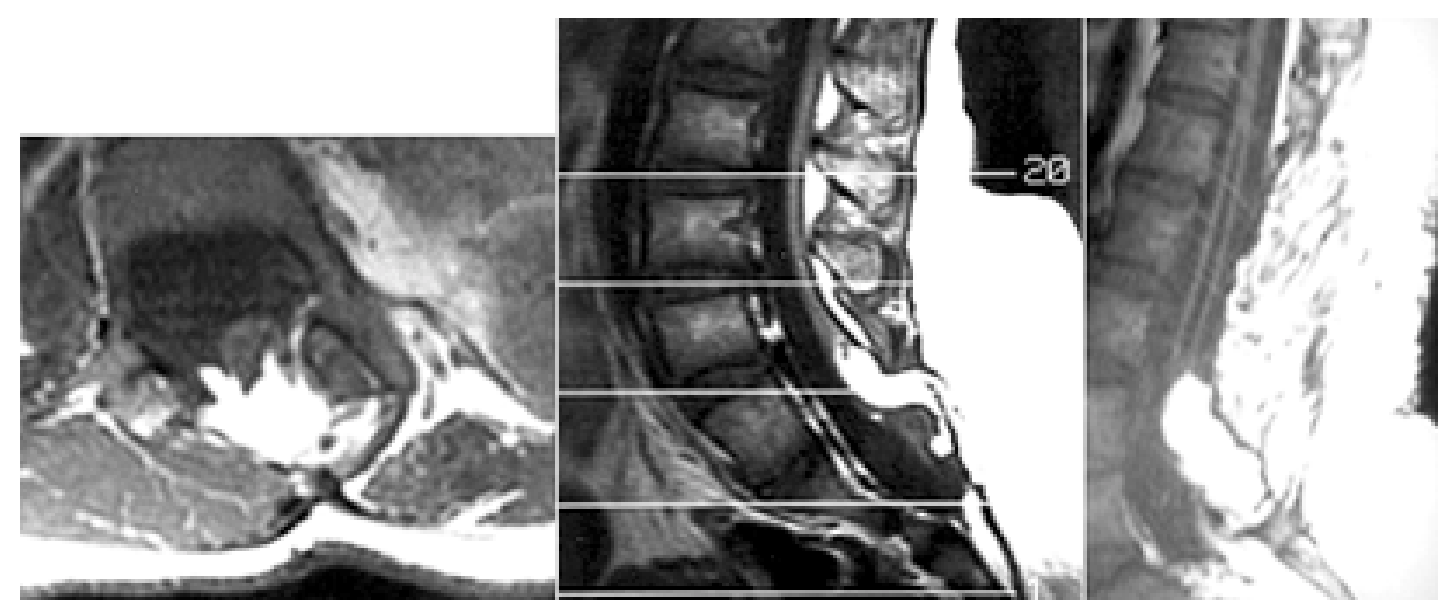

Fig. 3. Magnetic resonance imaging studies. Left: Axial $\mathrm{T}_{1}$-weighted image sequence without contrast, demonstrating fat of lipoma applied to the dorsal surface of dorsally displaced spinal cord. Center: Sagittal $\mathrm{T}_{1}$-weighted image of the lumbar spine without contrast, revealing caudal lipomyelomeningocele extending out of spinal canal, through a defect in bony lamina, and into the subcutaneous space. Right: Sagittal $\mathrm{T}_{1}$-weighted image revealing a caudal lipomyelomeningocele with low-lying conus (L3-4) and terminal syringomyelia.

al Days 19 to 21 the neural groove deepens and neural folds become visible. The folds continue to elevate and converge toward the midline. As the neural folds come together, the lateral cutaneous ectoderm also comes together in the midline and then fuses. Current understanding of myelomeningocele implicates a failure of the cutaneous ectoderm and neuroectoderm to fuse, such that the neural tube fails to close and remains dorsally applied to and continuous with the skin on its lateral surfaces. Lipomyelomeningoceles, by contrast, arise when disjunction between cutaneous ectoderm and neuroectoderm (neural tube) occurs early. As such, the cutaneous ectoderm has sealed, but the still-open neural tube is exposed for the ingrowth of paraxial mesoderm derived tissue. Presumably, the ectodermal surface of the exposed neural tube induces differentiation of this mesodermal tissue primarily into adipocytes, and a fatty mass subsequently develops. The source of the fat remains a controversial issue. ${ }^{12} \mathrm{~A}$ number of other tissues have been noted within the substance of a lipomyelomeningocele including striated muscle, cartilage, nerve cells, ependyma, and even cerebellum. The metabolism of the fat is the same as that of subcutaneous fat and does not show the accelerated metabolism of the lipoma. The metabolic features of the adipocytes within lumbosacral lipomas are similar to those of normal adipose tissue; however, these cells most commonly lie in a densely fibrous connective tissue stroma. Some have noted the multiple, different cell types present and have questioned whether the disorder in embryogenesis in fact gives rise to a benign form of teratoma. ${ }^{35}$

This model is consistent with the various surgically and radiologically recognized forms of lipomyelomeningocele (see below). In the caudal, form fatty tissue invaginates into the central canal and may ascend for several levels. An open neural tube would allow free access for mesodermally derived structures to become so positioned. A dorsally located lipomyelomeningocele arises directly off the back of the spinal cord and would presumably reflect a neural tube that had progressed farther toward complete closure.

\section{Lipomas of the Terminal Filum}

Unlike medllaris lipomas of the conus medullaris, those that arise in the filum are thought to develop as a result of a disorder of secondary neurulation. The neural tube that forms as a result of primary differentiation extends only as far as the second sacral segment. As such, it could not give rise to anomalies of the distal filum.

Secondary neurulation in humans is incompletely understood. Currently it is believed that progressive coalescence of vacuoles, which are seen to arise in the caudal cell mass during the 4th and 5th week of development, leads to the emergence of a central canal within the caudal cell mass. This canal is thought to coalesce with the neural tube that is formed by primary neurulation. The distal portion of the caudal cell mass is thought to regress to become the terminal filum. Presumably a disembryongenic process occurring at this developmental stage gives rise to the development of fat within the filum. The exact pathogenic mechanisms by which lipomas of the filum arise remain unknown, but impaired canalization of the caudal cell mass and persistence of cells capable of maturing into adipocytes are likely to be involved. This process occurs after disjunction of the cutaneous and neuroectoderm, and, as such, it is consistent that these lesions are skin covered and lacking cutaneous stigmata. The central canal of the caudal cell mass may persist as the terminal ventricle.

In a myelocystocele the terminal ventricle may become capped by lipoma which may impart abnormality to the CSF circulation and result in terminal ventricle dilation. McLone and Naidich ${ }^{44}$ hypothesize that the resulting meningocele impairs mesodermal structures resulting in spina bifida and cord tethering. ${ }^{29}$

Terminal myelocystocele is highly associated with anomalies of the genitourinary and gastrointestinal tracts. Structures related to the caudal spinal cord lie close to the cloaca during development. Thus, it is not surprising that anomalies of cloacally derived structures are highly associated with anomalies of the caudal spinal cord. Indeed, there is a high incidence of filum lipomas in patients in 
whom there are syndromes of cloacal maldevelopment including vertebral, anal, tracheal, esophageal, and renal anomalies; omphalocele (cloacal) exstrophy imperforale spinal anomalies and Currarino triad. Nonsyndromic associations include imperforate anus, rectovaginal fistulas, bladder extrophy, complex sacral malformations, ectopic kidney, and cecocutaneous peroneal fistulas. ${ }^{2,18,21,50,67}$

\section{TETHERING AND MECHANICAL SHEER}

Throughout the 1970s the goal of surgical treatment of lipomyelomeningocele was to reduce the mass associated with the lipoma and thereby improve the associated cosmetic defect. At that time surgeons understood that manipulation of the intradural portion of the defect was associated with an unacceptable risk of neurological decline. With greater study over a longer period of time, it has been learned that the connection between fibrofatty elements of the mass and the underlying conus medullaris serve to fix the conus medullaris and not allow it to ascend normally (Fig. 4). This mechanism is described as the tethered cord syndrome an is considered central to the pathophysiology of lipomas of both the conus medullaris (lipomyelomeningocele) and the filum (fatty filum). It is now recognized that an initial cosmetic operation is a risk factor for delayed postoperative neurological deterioration. ${ }^{10,36}$

Currently two hypotheses are favored to account for the observed neurological deterioration in the setting of a tethered cord: 1) that the tethering process results in a mechanical tension across the cord, which directly imparts neurological insult and 2) that the tension that develops adversely affects cord perfusion and causes an ischemic injury.

The elegant studies reported by Yamada, et al., ${ }^{74}$ have provided significant insight into the causes and effects of excessive cord stretching. In studies in a cat model of spinal cord tethering and stretching the authors have demonstrated that isotonic traction of the spinal cord results in different degrees of elongation in different cord segments. As such distal segments were most affected. These

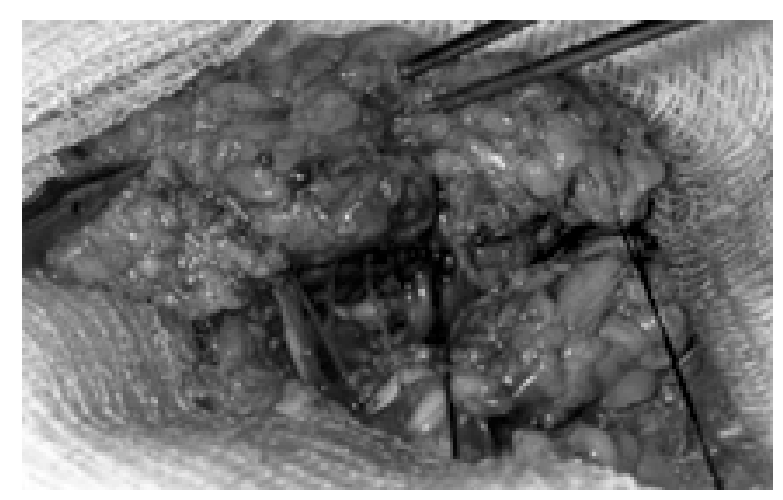

Fig. 4. The fibrofatty mass of a dorsal lipomyelomeningocele fixes the distal cord and prevents its normal ascension. Note the infiltration of underlying neural elements with the fatty fibrous tissue. With growth the cord gradually comes under tension, which is thought to be central in causing the progressive neurological deterioration that is the hallmark of the TCS. changes were mirrored by reduced oxidative metabolic values and evoked potentials. These findings are in keeping with the clinical observation of selective involvement of the lower extremities in clinical TCS. Additionally these investigators showed that severe traction of the spinal cord was associated with depression of spinal evoked potentials. Evoked potentials recovered after traction was released; however, interneuron potentials only partially recovered. The diminution of interneuron potentials appeared linked to changes in oxidative metabolism of the neurons. In additional studies, in this same report in which spectrophotometry of the cytochrome a, a3 was used to quantitate metabolic activities in a cat model of TCS, the results suggested that traction shifted the baseline redox ratio to a more reduced state. This finding implies either diminished adenosine triphosphate use or reduction of oxygen supply.

\section{BLOOD FLOW}

To study blood flow in a model of TCS, Yamada, et al., ${ }^{74}$ used hydrogen clearance on the dorsal surface of the cat spinal cord that was placed under a stretching condition. In this model blood flow decreased gradually as a traction weight was increased. When the weights were released, blood flow returned to normal. Kang, et al., ${ }^{31}$ similarly shown the development of impaired blood flow when longitudinal traction was applied on the spinal cord in a feline model of tethered cord. Schneider, et al. ${ }^{63}$ have recently reported that release of a tethered spinal cord is associated with increased spinal cord blood flow as demonstrated by laser Doppler flowmetry.

Although these hypotheses are in keeping with the progressive loss of function seen in most patients with untreated lipomyelomeningocele, there remain several clinical observations for which these concepts do not account.

First, in some patients with lipomyelomeningocele progressive neurological decline is not shown. Whereas it is widely recognized that older patients have more symptoms (thus supporting the general notion that early surgical untethering is appropriate), it is also noted that there is significant variability in the degree of symptoms manifested by patients of differing ages. ${ }^{42,52}$ Indeed, there are isolated case reports of adults with lipomyelomeningocele and no apparent neurological deficit. It is emphasized that we do not consider these rare cases as indicative of a benign natural history of untreated lipomyelomeningocele, nor do such cases justify a conservative approach to the management of spinal lipomas. They do, however, attest to variability in the extent to which different patients are affected and prompt us to consider whether an additional mechanism could be causing injury to the cord.

Second, the majority of patients who undergo an untethering procedure experience significant prolonged benefit. In many patients late-onset neurological deterioration is demonstrated (months to years following untethering) that is attributed to retethering. Why all patients do not experience immediate retethering as a result of normal scar tissue formation is uncertain. If fibrosis occurs following tethered cord release, as it does in a similar fashion following other operative procedures, one could reasonably anticipate a period of weeks or months in which the un- 
tethered cord was truly free. Neurological deterioration in such a short time, however, is remarkably rare. This suggests that the pathophysiological event is acting apart from simple connection-related traction.

Third, patients presenting with delayed-onset neurological deterioration following an untethering procedure are thought to have a retethered cord and are often offered repeated surgery in another attempt to untether the cord. Such procedures are recognized to be more difficult, carry higher risks of neurological insult, and have a lower success rate in preventing neurological decline. During some such repeated procedures, a complete anatomical untethering occasionally cannot be accomplished because the apparently intact neural structures, which are integrally related to a mass of scar tissue, must not be put at risk. However, even in the absence of complete anatomical untethering, significant clinical improvement often is sustained in many such patients. If the anatomical tether is not disconnected, the current hypotheses cannot account for such improvement of the pathophysiology in the TCS.

\section{OTHER POSSIBLE CAUSES OF NEUROLOGICAL DETERIORATION}

Perhaps there are additional mechanisms operating in the setting of a tethered cord that may cause injury to neural tissue. One such possibility is that the tethering adversely affects the cord's capability to move and, thus, diminishes the impact of the pulsations of the CSF. The cord normally hangs free in the subarachnoid space and is fixed only superiorly at the level of the foramen magnum. Lateral fixation by the dentate ligaments is minimally restrictive. As such, it is anticipated that the normal cord moves freely. If the cord becomes distally fixated by a tethering mechanism, then one can speculate that the free movement of the cord may become reduced and, thus, that the cord may have to absorb fluid dynamic stresses imparted by the pulsatile CSF. Such stresses may otherwise have been dampened by cord movement. Perhaps there are fluid dynamic waves that act constructively to increase the degree of insult on the cord. The cumulative impact of a CSF pressure wave-associated with thousands or millions of heartbeats in the setting of a fixed cord-could conceivably, over time, impart neurological damage. This hypothesis does not negate or disprove previous notions of the cause of tethering-induced cord dysfunction. Indeed, the impact of fluid dynamics may be more important in a cord already compromised by mechanical sheer forces or ischemia.

The variability of neurological decline could be attributed to differences in CSF flow dynamics and tethered cord in affected individuals. Clearly the patterns of pressure waves in the spinal CSF are highly complex and related to multiple factors, including the relative size of cord and canal, cord vasculature, and the fixation points of the cord. There is likely adequate variability to account for the disparate symptoms observed in clinical practice. Although the typical scenario would involve neurological decline, there could conceivably be those individuals in whom the pattern of tethering allowed the cord to move adequately to diminsh the pulsations of the CSF.

\section{CLASSIFICATION OF LIPOMAS}

\section{Lipomas of the Conus Medullaris}

A classification system that is valuable reflects the anatomical features and/or natural history of a lesion or disorder so as to facilitate an organized and logical therapeutic approach to its treatment. Chapman, alone ${ }^{16}$ and with Davis $^{17}$ has described such a system for lipomyelomeningoceles that broadly divides them into two distinct variants and a transitional form. This system is of particular value to the surgeon as it enables him or her to anticipate the location of neural structures, meningeal coverings, and the site of tethering in relation to the fatty mass. ${ }^{15}$

Dorsal Variant. The dorsal variant (Fig. 5) is a lipoma that arises through a fascial defect and attaches directly to the dorsal aspect of the caudally descended conus medullaris; all nerve roots emerge from the ventral or lateral surface of the neural tissue and lie in the subarachnoid space. The lateral nerve roots are sensory, and the more medial nerve roots are motor roots. Critical to the surgical approach is the junction formed by the lipoma and the spinal cord complex, as well as the position of the dural attachment in relation to that complex. ${ }^{16}$

Caudal Variant. The caudal variant (Fig. 6) is a lipoma that exits the area of the terminal filum so that the cord becomes progressively larger caudally. In this form of lipomyelomeningocele, the nerve roots do transgress the

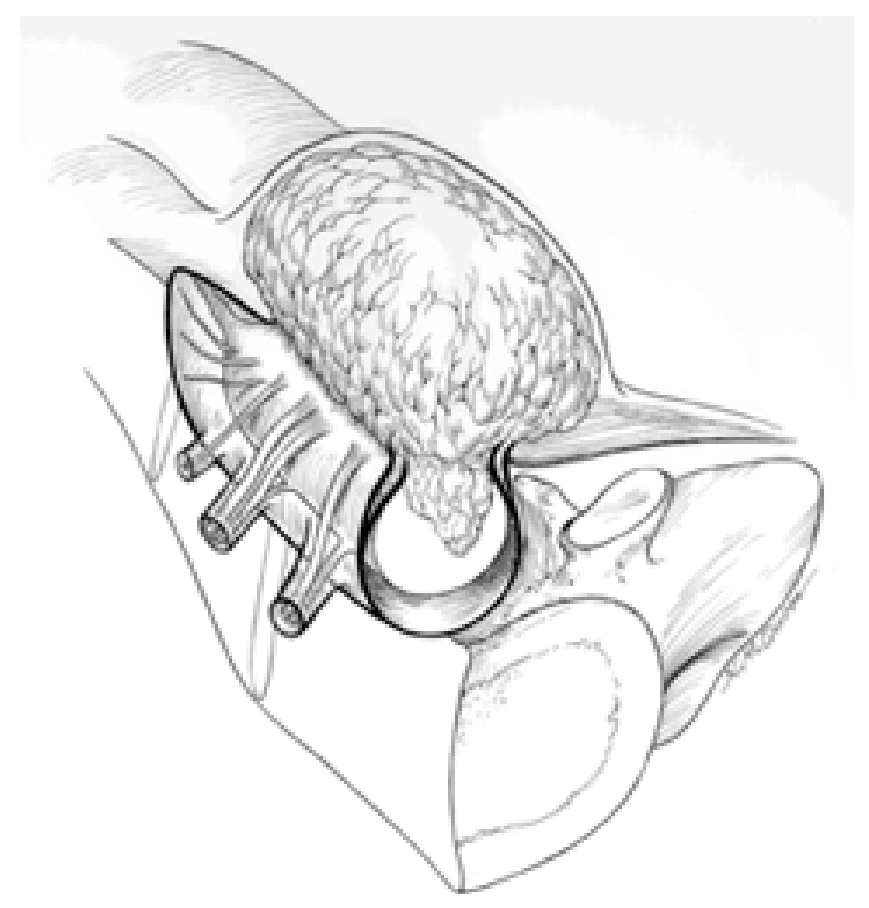

Fig. 5. Drawing of a dorsal lipomyelomeningocele. The lipoma is fixed to the dorsal surface of the conus medullaris. The nerve roots emerge from the spinal cord immediately anterior to the zone where the lipoma, dura, and conus meet. The associated fatty accumulation penetrates a bone and fascial defect and is in direct continuity with a large subcutaneous fat accumulation. Often the filum is thickened and infiltrated by fat. Adapted with permission from Oakes. 


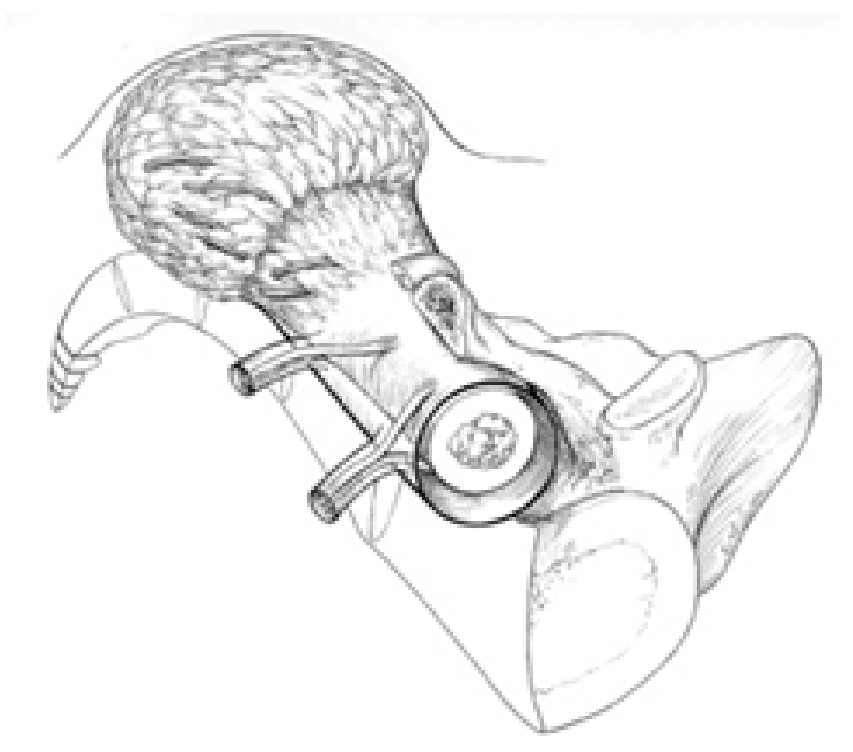

Fig. 6. Drawing of a caudal lipomyelomeningocele. Fat extends from within the central canal of the cord through the caudal end where it intermixes with exiting nerve roots. A transverse fibrous band is often present at the level of the last intact lamina. Release of this band may result in dural expansion. Adapted with permission from Oakes.

lipoma. Many of these nerve roots are thought to be nonfunctional and can be sacrificed after stimulation. Although this caudal variation is difficult to reform into a tubular structure, the cut end of the lipoma may retract sufficiently cephalad to lessen the likelihood that retethering will occur postoperatively. ${ }^{16}$

Transitional Forms. The transitional form (Fig. 7) has elements of both dorsal and caudal variants. Viable nerve roots pass through significant amounts of lipoma before exiting. Typically these are asymmetrical and associated with a rotational component of the spinal cord. ${ }^{16}$

The process of distinguishing among these three types of lipoma is usually straightforward; however, in the literature scant regard is often given to the differences. Specifically lipomas of the conus medullaris and those of the terminal filum are frequently considered as a single entity, an assumption that is not justified on the basis of longterm follow-up studies in children with such lesions.

\section{Lipomas of the Terminal Filum}

There is currently no widely used classification system for lipomas of the terminal filum nor is there one described in the literature. Because they have only become commonly diagnosed since the advent of MR imaging, much remains to be learned about these lesions. As such, the natural history of filum lipomas is incompletely understood. As noted earlier a meaningful classification system will either correlate with natural history and/or facilitate a therapeutic approach.

To create a classification system it is reasonable to begin by distinguishing those lesions in which the conus medullaris is at the normal age-specific position from those in which the conus medullaris is abnormally low lying. Another reasonable criterion for distinguishing

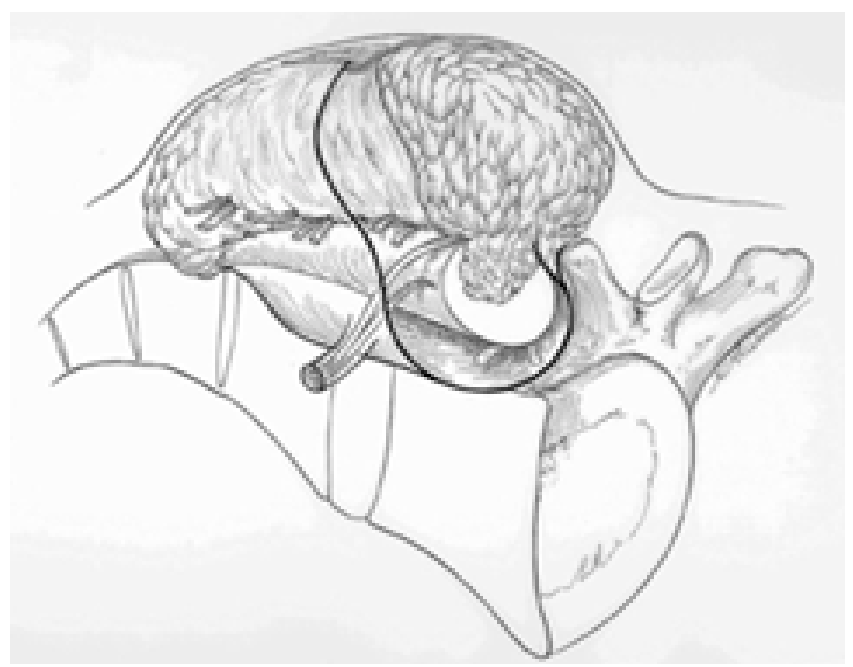

Fig. 7. Drawing of a transitional lipomyelomeningocele. This lesion demonstrates components of both dorsal and caudal variants of lipomyelomeningoceles.

these lesions would be the presence of pain or neurological signs (symptomatic or asymptomatic). Thus, these lesions could be broadly classified into one of four patterns: 1) fatty filum with descended conus medullaris and symptoms, 2) fatty filum with descended conus medullaris and no symptoms, 3) fatty filum with normal conus medullaris position and symptoms, and 4) fatty filum with normal conus medullaris position and no symptoms. The relative importance of other issues such as thickness of the filum, relative amount of fat, or presence of spina bifida occulta is less clear.

\section{SURGICAL TREATMENT}

\section{Lipomas of the Conus Medullaris}

The role of surgery in cases of lipomyelomeningocele remains controversial. ${ }^{68}$ For the patient in whom symptoms or neurological deficits are present there is little controversy. Because of an unclear natural history, a significant incidence of perioperative neurological insults, postoperative complications (in some series), and a high rate of late neurological deterioration, some authors have been reluctant to advocate a prophylactic untethering procedure in the asymptomatic child. ${ }^{28}$

The natural history of untreated lipomyelomeningocele is imperfectly understood. Ethical issues preclude a methodologically perfect investigation in which, in a prospective manner, surgical resection and untethering is offered to one group of patients and denied to another matched group. In the absence of prospective data some consider it proper to pursue a conservative approach to spinal lipomas. Howeve r, indirect evidence obtained from multiple centers around the world supports the idea that pain, orthopedic deformity, and/or progressive neurological decline will develop in an asymptomatic child who harbors an untreated lipomyelomeningocele. ${ }^{6,8,10.20,64} \mathrm{Ka}$ nev and Bierbrauer ${ }^{30}$ have shown that neurological deterioration demonstrates a logarithmic relationship with advancing age. Further evidence culled from large series 
suggests that loss of neurological function is unlikely to be regained in the majority of cases. ${ }^{10,27,40,60}$ Pain is quite amenable to surgical treatment even in adults; however, bladder function, once impaired, is not likely to be recovered. ${ }^{11,22,23,27,30,60,72} \mathrm{Wu}$, et al., ${ }^{72}$ have found that the principal determinant of long-term bladder outcome was the patient's preoperative bladder status. Once neurologically related bladder dysfunction has occurred, the likelihood that normal bladder control will return is less than $20 \% .^{30,46}$ As such, we support the opinion held by the majority of pediatric neurosurgeons that surgical exploration of lipomyelomeningoceles is warranted before neurological deterioration occurs. ${ }^{6,30}$ The goals of such an exploration would include exposure of the plane between lipoma and spinal cord so that complete separation between the cord and the subcutaneous fibrofatty mass can occur and be followed by watertight closure of the dura and wound.

\section{Surgical Technique and Approach}

Following induction of general anesthesia and placement of appropriate intravenous lines and a Foley catheter, monitoring electrodes are placed in the muscles of the lower extremities to facilitate intraoperative nerve monitoring. The patient is then placed in the prone position, and pressure points are carefully padded. Following a routine surgical preparation, a linear midline incision is made that extends above and below the fatty lump on the back. After inferior and lateral dissection the lumbodorsal fascia can be identified circumferentially around the fatty mass. By working with blunt dissection (we find a Kittner dissector useful) lateral to medial along the surface of the lumbodorsal fascia the defect in the lumbo dorsal fascia, becomes evident. Occasionally the distal portion of the mass will blend with the muscular fibers of the gluteus maximus. The mass can often be significantly reduced at this point; however, it is critical to retain enough mass to maintain control of the lipoma.

Attention is then turned to the level above the defect, and the paraspinous muscle is separated on the midline. Monopolar cautery is used to isolate the first spinous process. A subperiosteal dissection is performed and selfretaining retractors are placed. Next, a laminectomy is performed to expose normal dura. Dorsal lipomas project through the lumbodorsal fascia and attach directly to the back of the descended conus medullaris. The nerve roots characteristically exit laterally or ventrally. Because caudal lipomas extend off of the distal end of the cord and envelop the exiting nerve roots in the substance of the lipoma, they may extend rostrally up the central canal of the cord for many levels. It is crucial to establish surgeryrelated goals clearly prior to beginning the procedure. Experience indicates that gross-total resection is not necessary and in fact carries an unacceptable risk of causing neurological injury. The primary surgery-related objective in the excision of a spinal lipoma is to remove enough of the mass so that normal anatomical planes may be surgically reconstructed. Some authors have advocated use of the $\mathrm{CO}_{2}$ laser for this purpose because it selectively dissolves fatty tissue with a minimum of contact or retraction., ${ }^{3,46}$ We have found the ultrasonic aspirator to be a very useful for the internal debulking of these lesions
(Video Clips 1-11). Once the dorsal plane of the spinal cord is appreciated, internal debulking of the lipoma is accomplished using the ultrasonic aspirator. Enough fat is resected to facilitate reconstruction of the neural tube within the dural sleeve. We have found this technique more efficient than the laser, and we use the laser selectively only for the last remaining bits of residual lipoma before closure is initiated.

\section{Video Clips.}

Clip 1: Cutaneous dermal sinus tract. The tract base aims superiorly as it is moved in a caudal direction.

Clip 2: Opening the dura. The dura is opened linearly above the lipomyelomeningocele and then widely around the lesion. The durais tacked up.

Clip 3: Tacking up the dura. The dura is tacked back by retention sutures in the usual fashion.

Clip 4: Opening the lipomyelomeningocele. The arachnoid over the linoma is sharply opened; in this case microscissors were used.

Clip 5: Debulking the lipomyelomeningocele with the ultrasonic aspirator. This may also be performed using the laser, depending on the surgeons' preference.

Clip 6: Further debulking of the lipomyelomeningocele with the ultrasonic aspirator. This is conducted until a thin remnant of the lipoma remains.

Clip 7: Bipolar coagulation within the confines of the lipomyelomeningocele.

Clip 8: Sharp dissection of arachnoidal scar that tethers the lipomvelomeningocele to dura.

Clip 9: Initial closure of the resection cavity. The pial edges are reapproximated with No. 7-0 PDS inverted sutures to reduce the surface area available to form scar tissue and subsequent retethering

Clip 10: Middle stage of the resection cavity closure procedure Clip 11: Final closure of the resection cavity. The dura may then be closed primarily, or a patch may be placed to provide a more capacious thecal sac.

Fatty and fibrous connections between the conus medullaris and paraspinous soft tissues are disconnected, thereby freeing the cord from tethering. To accomplish these objectives it is critical to establish the plane between the lipoma and the dorsal surface of the spinal cord during the dissection. Once this plane is appreciated, circumferential dissection can usually free the cord of its fatty attachments. Particular care needs to be taken laterally in the cul-de-sac in caudal lipomas as this is where exiting nerve roots can become lost and inadvertently injured or divided if care is not taken by the surgeon. Exiting nerve roots in the substance of the fatty fibrous tissue are at constant risk. Small fibrotic rootlets may be divided. Intraoperative monitoring (rectal electromyography, urethral electromyography, somatosensory evoked potentials, and rectal or bladder pressure) has proven to be a very useful adjunct for some surgeons in the dissection of viable neural tissue in the midst of a mass of fibrofatty tissue. ${ }^{55,66}$ The use of monitoring depends on the experience of each surgeon.

Closure must then be performed with great care. Ideally the dural closure will be capacious enough that no contact remains between the distal cord and the dura. Tight reapproximation of the dura so as to cause constriction must be avoided. Often caudal lipomas are difficult to reestablish into a proper tube. Some authors have advocated the utility of a synthetic patch to help make the dura more ca- 
pacious. ${ }^{77}$ Layer-by-layer closure is accomplished in a systematic and compulsive means so as to reduce the likelihood of postoperative CSF leaks. Some surgeons advocate a minimal removal of subcutaneous fat because they believe that an enlarged fat pad provides an effective barrier against a postoperative $\mathrm{CSF}^{27}$ We recommend prescribing a period of 5 days of flatbed rest in the immediate postoperative period to further help reduce the likelihood of postoperative CSF leaks.

\section{Lipomas of the Terminal Filum}

In any rational consideration for surgical intervention the risk or the natural history of the untreated disease is weighed against the risk of the proposed surgical intervention. Because the natural history of terminal filum lipomas is incompletely understood, it is impossible to make recommendations with certainty. Nonetheless, the collective weight of evidence from multiple centers reporting ${ }^{39,55,56}$ series of filum lipomas supports the notion that an enlarged fatty filum in which the conus medullaris is displaced is highly associated with a tethered spinal cord. Thus, the natural history of the untreated condition for those patients with fat in an enlarged filum and an abnormally caudally displaced conus medullaris can be reasonably anticipated to include progressive pain and neurological deterioration. Greater controversy surrounds the treatment of cases in which the usual clinical findings of the tethered cord are demonstrated because neuroimaging reveals the conus medullaris to be at a normal position. In such studies ${ }^{70,71}$ the authors also report very low rates of complications associated with the division of such fatty filums. As such, an aggressive surgical approach seems warranted for those patients with a Grade 1 lipoma of the filum. Optimal therapy for asymptomatic patients or those in whom a normal conus medullaris position is shown is less clear. ${ }^{69,70}$ Because we have found a low rate of complications associated with the surgical division of an enlarged filum, we have recommended that patients with either progressive symptoms or an abnormal conus medullaris position in conjunction with an enlarged fat infiltrated filum undergo surgical division of the fatty filum (Table 1). We emphasize, however, during the informed consent discussion with families of patients harboring Grade 2 or 3 lesions that the natural history of filum lipomas is unknown, that improvement in symptoms cannot be assured, and that the risks of the procedure, although real, are very low.

\section{Surgical Approach}

In cases of lipoma of the terminal filum the surgical ob- jective is to interrupt the abnormal connection between the hypertrophied and fat-infiltrated filum with the conus medullaris. Because this is most simply accomplished by sectioning the enlarged filum, the surgical undertaking is significantly less challenging than that of a lipomyelomeningocele.

Usually the enlarged filum can be readily discerned from the exiting nerve roots of the cauda equina beneath the operating microscope. It usually is larger, has longitudinal striations, appears different in color (typically described as somewhat more pink or gray than the generally ivory colored exiting nerve roots), and is often apparent by virtue of the mass of infiltrating fat. Nonetheless, intraoperative monitoring may be useful in providing greater assurance that the structure cut is not an exiting nerve root. Therefore, the use of intraoperative monitoring is left to the discretion of the individual neurosurgeon.

Once general anesthesia is induced the patient is placed prone on rolls or a frame. It is not typically necessary to insert a Foley catheter. After the lumbar region is prepared, antibiotic agents are provided, and the patient is draped, a midline incision is made in the lumbar region. The site of the incision is approximated in the lumbosacral region to be over a region where the filum is robust and between two laminae. The paraspinous musculature is removed via subperiosteal dissection to expose adjacent laminae and spinous processes. Most of the work can be performed between the laminae; however, it is often useful to remove a small portion of the inferior aspect of the superior lamina (to the level of the spinous process) and a similar small portion of the superior aspect of the inferior lamina (also to the level of the spinous process). The ligamentum flavum is removed to create a small corridor of access to the dura. The dura is then opened, and dural retaining sutures are placed. The operating microscope is brought in, and the cauda equina is inspected. The hypertrophied filum is typically readily evident. Intraoperative monitoring may be used for stimulation of the filum prior to its transection to provide the surgeon with additional assurance that an important neural structure is not being divided. The filum is coagulated with bipolar coagulation as there is typically a small vein within the filum. Often the filum will significantly retract in length. We prefer to remove a segment of the affected filum and submit it to pathological examination for confirmation that the transected structure was terminal filum. Watertight dural closure followed by meticulous layer-by-layer closure finalize the operative procedure. The overall operation time is typically less than 90 minutes and is associated with a complication rate of less than $5 \%$.

TABLE 1

Classification system for lipomas of the terminal filum

\begin{tabular}{|c|c|c|c|c|}
\hline Grade & Filum appearance & $\begin{array}{c}\text { Position of } \\
\text { Conus Medullaris }\end{array}$ & Symptoms & Surgical Approach \\
\hline 1 & fat w/in thickened filum & abnormally descended & yes & clipping of fatty filum \\
\hline 2 & fat w/in thickened filum & abnormally descended & no & clipping of fatty filum (prophylactic) \\
\hline 3 & fat w/in thickened filum & normal & yes & $\begin{array}{l}\text { clipping of fatty filum (after meticulous \& com- } \\
\text { prehensive evaluation for other sources) }\end{array}$ \\
\hline 4 & fat w/in thickened filum & normal & no & clinical observation \\
\hline
\end{tabular}




\section{COMPLICATIONS}

\section{Lipomas of the Conus Medullaris}

Wound-Related Complications. Despite careful attention, the authors of several large series have reported significant rates of postoperative wound complications (infections, CSF leaks, and wound breakdown) that range from 10 to $20 \% .^{17,30,46,54,56}$ Careful attention to closure is therefore imperative. Some surgeons favor several days of flat bedrest in the immediate postoperative period as a measure to decrease the likelihood of CSF leaks.

Acute Neurological Decline. The risk of surgery-related neurological deterioration was at one time thought prohibitively high; as such, only a limited debulking of the subcutaneous mass was undertaken. With greater understanding of the anatomy and natural history of lipomyelomeningoceles a more aggressive surgical approach has become widely supported. ${ }^{15}$ In addition to conceptual advances, technical developments including improved operating microscopes, better illumination, improved microsurgical instruments, refined lasers, and advances in intraoperative monitoring have all contributed to surgeryrelated advances. In using these adjuncts the authors of most contemporary series report a 1 to $2 \%$ surgery-related risk of neurological deterioration.

Retethering of the cord and late-onset deterioration remains the greatest risk for patients undergoing resection of a lipomyelomeningocele. ${ }^{5,73}$ Although reduction of the fatty mass and placement of dural substitute grafts has been used to prevent dural constriction and subsequent risk of retethering, it is apparent that in a significant percentage of patients late retethering is demonstrated which is clinically manifested as delayed neurological deterioration. ${ }^{19}$ Colak, et al., ${ }^{19}$ reported that 19 of 94 patients who underwent surgery for lipomyelomeningocele required 28 subsequent operations for symptomatic retethering. Pierre-Kahn and colleagues ${ }^{56}$ reported that only $53 \%$ of patients who underwent surgery for lipomyelomeningocele were symptom free at an average of more than 5 years of follow up. Of the $6 \%$ of these patients who underwent reoperation, further improvement was demonstrated in $31 \%$, arrested progression in $44 \%$, and continued deterioration in $19 \%$. The rate of late-onset neurological deterioration in this report is higher than other recently reported series. ${ }^{56}$ This observation has been taken by some authors to suggest that initial surgery before the lesion becomes symptomatic does not alter the natural history of the disease and to support a conservative approach to the treatment of spinal lipomas. ${ }^{28}$

$\mathrm{Wu}$, et al., ${ }^{72}$ have recently reported that in $84 \%$ of patients undergoing repair of a lipomyelomeningocele before age 1.5 years stable clinical and urodynamic functions were maintained. Late-onset neurological deterioration was observed in $16 \%$, and this occurred between 9 months and 8 years postoperatively. In their series the best predictor of long-term bladder function was preoperative urodynamic status.

$\mathrm{Wu}$, et al., concluded that early diagnosis and surgical intervention is warranted, but follow-up study must continue for years because retethering was seen up to 8 years following surgery. In other recent series the authors have documented rates of delayed-onset deterioration of 3.3 to
$5 \%$ over follow-up periods ranging from 6 months to over 20 years. $^{59}$

\section{Lipoma of the Terminal Filum}

Wound-Related Complications. As the overlying planes of tissue are normal in lipomas of the terminal filum the closure of the wound is simplified and woundrelated problems are less common. Incidences of woundrelated complications of less than $3 \%$ have been reported in large series. ${ }^{38}$

Neurological Complications. New deficits are exceedingly uncommon following release of a fatty filum. La Marca, et al., ${ }^{38}$ have recently reported that of 55 pediatric patients who presented with a lipoma of the terminal filum, 28 were asymptomatic at the initial operation and 27 presented with symptoms. Of the asymptomatic children, none worsened after surgery, and all remained asymptomatic throughout more than mean of follow-up period of 3 years. ${ }^{38}$ Pierre-Zahn and colleagues ${ }^{55}$ reported no worsening of functioning at more than 5 years postoperatively in a group of patients who underwent division of a filum lipoma. Although the risk of retethering appears very low Souweidane and Drake ${ }^{66}$ have reported on two patients in whom retethering was demonstrated following division of a lipoma of the terminal filum.

\section{FOLLOW-UP STUDY}

Careful follow up of patients who underwent resection of a lipomyelomeningocele is important because of the risk of delayed neurological deterioration from retethering. After a series of acutecare postoperative visits at 1, 3, and 6 months, these patients typically attend annual follow-up visits until they reach adulthood. Occasionally when a family appears particularly attentive and well informed such that our concern of missing signs of neurological decline is reduced, we will see these patients once every 2 years. The most important component to follow up is the patient's clinical history. Whereas some authors support the undertaking of urodynamic studies in following these patients, we have not found this to be a useful adjunct. Our decision to conduct surgical reexploration instead of simply following these patients is based on recurrence of pain or evidence of neurological decline. An imaging study is typically only obtained once a decision to operate has already been made on clinical grounds.

Rarely growth of spinal lipomas may be found on sequential imaging studies, and lipomas have occasionally recurred after resection. Lipomas will typically enlarge with age in proportion to body growth so that significant weight gain, particularly if associated with obesity, may contribute to recurrence of spinal lipomas. Malignant transformation is exceedingly rare.

\section{Intradural Spinal Lipomas}

Lipomas of the spinal cord are considered to behave as spinal cord tumors that cause neurological deficit as a result of their mass effect. ${ }^{43}$ Perhaps best considered as congenital inclusion tumors of the central nervous system, they represent approximately $1 \%$ of all spinal cord tumors. ${ }^{24}$ These lesions are intradural and vary with regard 
to their relationship to the spinal cord. ${ }^{37}$ Some are completely intramedullary whereas others are part intramedullary and part extramedullary. ${ }^{53}$ They are typically thoracic in location, although the cervical region is most common in children. ${ }^{25,34,71,76}$ Lipomas of the spinal cord typically present in the second and third decade of life. Lee, et al., ${ }^{39}$ have described a series of six patients harboring these lesions who typically presented with long histories of disability followed by rapid progression of symptoms, and most patients were in poor neurological condition on presentation. The presenting symptoms included spinal pain, dysesthetic sensory changes, gait difficulties, weakness, and incontinence.

Surgical management is aimed at elimination of mass effect. The relationship of the lipoma to the spinal cord is the critical determinant of the of resection that may be obtained. Because these lesions are very slow growing and cause neurological insult secondary to mass effect, a very satisfactory and long-lasting clinical effect may be obtained after achieving a subtotal excision.

\section{Surgical Approach}

With the patient in the prone position a midline incision is made. Because the skin and soft tissues typically appear to be normal, localization can be challenging. It is often useful to place a vitamin $E$ capsule on the skin at the time the MR imaging is performed to allow skin marking for incision planning. Alternately intraoperative preincision plain x-ray films may be obtained and compared with preoperative images position the incision to optimally.

Once the incision is made, a midline approach and subperiosteal dissection is pursued. The number of laminae removed depends on the size of the underlying lesion. Once the laminectomy has been performed, intraoperative ultrasonography can be very useful in confirming proper localization before the dura is opened; additionally, this modality can be helpful in deciding whether more laminae need to be removed. Dural opening and retention sutures then are placed, and the lipoma is inspected under the operating microscope. A combination of $\mathrm{CO}_{2}$ laser and/or ultrasonic aspiration is used to reduce the mass of the lesion to the maximum extent that is safe. Intraoperative monitoring may be very useful, particularly if cord retraction or rotation is anticipated for optimum exposure of the lesion. Once maximal mass effect is relieved a thorough layer-bylayer closure ensues to minimize the likelihood of CSF leaks.

\section{References}

1. Anson JA, Cybulski GR, Reyes M: Spinal extradural angiolipoma: a report of two cases and review of the literature. Surg Neurol 34:173-178, 1990

2. Appignani BA, Jaramillo D, Barnes PD, et al: Dysraphic myelodysplasias associated with urogenital and anorectal anomalies: prevalence and types seen with MR imaging. AJR 163: 1199-1203, 1994

3. Ascher PW, Heppner F: $\mathrm{CO}_{2}$-laser in neurosurgery. Neurosurg Rev 7:123-133, 1984

4. Atala A, Bauer SB, Dyro FM, et al: Bladder functional changes resulting from lipomyelomeningocele repair. J Urol 148: 592-594, 1992

5. Barolat G, Schaefer D, Zeme S: Recurrent spinal cord tethering by sacral nerve root following lipomyelomeningocele surgery. Case report. J Neurosurg 75:143-145, 1991
6. Begeer JH, Wiertsema GP, Breukers SM, et al: Tethered cord syndrome: clinical signs and results of operation in 42 patients with spina bifida aperta and occulta. Z Kinderchir 44 (Suppl 1):5-7, 1989

7. Brophy J, Sutton L, Zimmerman R: Magnetic resonance imaging of lipomyelomeningocele and tethered cord. Neurosurgery 25:336-341, 1989

8. Bruce DA, Schut L: Spinal lipomas in infancy and childhood. Childs Brain 5:192-203, 1979

9. Brunberg JA, Latchaw RE, Kanal E, et al: Magnetic resonance imaging of spinal dysraphism. Radiol Clin North Am 26: 181-205, 1988

10. Byrne RW, Hayes EA, George TM, et al: Operative resection of 100 spinal lipomas in infants less than 1 year of age. Pediatr Neurosurg 23:182-186, 1995

11. Caruso R, Cervoni L, Fiorenza F, et al: Occult dysraphism in adulthood. A series of 24 cases. J Neurosurg Sci 40:221-225, 1996

12. Catala M: Embryogenesis. Why do we need a new explanation for the emergence of spina bifida with lipoma? Childs Nerv Syst 13:336-340, 1997

13. Cecchini A, Locatelli D, Bonfanti N, et al: Lipomyelomeningoceles: a neuroradiological approach. J Neuroradiol 15:49-61, 1988

14. Chakrabortty S, Oi S, Yoshida Y, et al: Myelomeningocele and thick filum terminale with tethered cord appearing as a human tail. Case report. J Neurosurg 78:966-969, 1993

15. Chapman P, Stieg PE, Magge S, et al: Spinal lipoma controversy. Neurosurgery 44:186-192, 1999

16. Chapman PH: Congenital intraspinal lipomas: anatomic considerations and surgical treatment. Childs Brain 9:37-47, 1982

17. Chapman PH, Davis KR: Surgical treatment of spinal lipomas in childhood. Pediatr Neurosurg 19:267-275, 1993

18. Chestnut R, James HE, Jones KL: The Vater association and spinal dysraphia. Pediatr Neurosurg 18:144-148, 1992

19. Colak A, Pollack IF, Albright AL: Recurrent tethering: a common long-term problem after lipomyelomeningocele repair. Pediatr Neurosurg 29:184-190, 1998

20. Colak A, Tahta K, Ozcan OE, et al: Congenital lumbosacral lipomas presenting as a form of occult spinal dysraphism. A report of 9 surgically treated cases. Zentralbl Neurochir 53: 15-19, 1992

21. Davidoff AM, Thompson CV, Grimm JM, et al: Occult spinal dysraphism in patients with anal agenesis. J Pediatr Surg 26: 1001-1005, 1991

22. Fone PD, Vapnek JM, Litwiller SE, et al: Urodynamic findings in the tethered spinal cord syndrome: does surgical release improve bladder function? J Urol 157:604-609, 1997

23. Foster LS, Kogan BA, Cogen PH, et al: Bladder function in patients with lipomyelomeningocele. J Urol 143:984-986, 1990

24. Fujiwara F, Tamaki N, Nagashima T, et al: Intradural spinal lipomas not associated with spinal dysraphism: a report of four cases. Neurosurgery 37:1212-1215, 1995

25. Gower DJ, Engles CF, Friedman ES: Thoracic intraspinal lipoma. Br J Neurosurg 8:761-764, 1994

26. Gupta RK, Sharma A, Jena A, et al: Magnetic resonance evaluation of spinal dysraphism in children. Childs Nerv Syst 6: $161-165,1990$

27. Hoffman HJ, Taecholarn C, Hendrick EB, et al: Management of lipomyelomeningoceles. Experience at the Hospital for Sick Children, Toronto. J Neurosurg 62:1-8, 1985

28. Jamil M, Bannister CM: A report of children with spinal dysraphism managed conservatively. Eur J Pediatr Surg 2 Suppl 1:26-28, 1992

29. Kanev P, Berger M: Lipomyelomeningocele and myelocystocele, in Youmans JR (ed): Neurological Surgery. Philadelphia: WB Saunders, 1996, Vol 2, pp 861-872

30. Kanev PM, Bierbrauer KS: Reflections on the natural history of lipomyelomeningocele. Pediatr Neurosurg 22:137-140, 1995 
31. Kang J, Kim M, King D: Effects of tethering on regional spinal cord blood flow and sensory-evoked potentials in growing cats. Childs Nerv Syst 3:35-39, 1987

32. Kaplan JO, Quencer RM: The occult tethered conus syndrome in the adult. Radiology 137:387-391, 1980

33. Klekamp J, Raimondi AJ, Samii M: Occult dysraphism in adulthood: clinical course and management. Childs Nerv Syst 10: 312-320, 1994

34. Kodama T, Numaguchi Y, Gellad FE, et al: Magnetic resonance imaging of a high cervical intradural lipoma. Comput Med Imaging Graph 15:93-95, 1991

35. Koen JL, McLendon RE, George TM: Intradural spinal teratoma: evidence for a dysembryogenic origin. Report of four cases. J Neurosurg 89:844-851, 1998

36. Koyanagi I, Iwasaki Y, Hida K, et al: Factors in neurological deterioration and role of surgical treatment in lumbosacral spinal lipoma. Childs Nerv Syst 16:143-149, 2000

37. Kujas M, Sichez JP, Lalam TF, et al: Intradural spinal lipoma of the conus medullaris without spinal dysraphism. Clin Neuropathol 19:30-33, 2000

38. La Marca F, Grant JA, Tomita T, et al: Spinal lipomas in children: outcome of 270 procedures. Pediatr Neurosurg 26:8-16, 1997

39. Lee M, Rezai AR, Abbott R, et al: Intramedullary spinal cord lipomas. J Neurosurg 82:394-400, 1995

40. Lellouch-Tubiana A, Zerah M, Catala M, et al: Congenital intraspinal lipomas: histological analysis of 234 cases and review of the literature. Pediatr Dev Pathol 2:346-352, 1999

41. Lhowe D, Ehrlich MG, Chapman PH, et al: Congenital intraspinal lipomas: clinical presentation and response to treatment. J Pediatr Orthop 7:531-537, 1987

42. Maiuri F, Gambardella A, Trinchillo G: Congenital lumbosacral lesions with late onset in adult life. Neurol Res 11:238-244, 1989

43. McGillicuddy GT, Shucart W, Kwan ES: Intradural spinal lipomas. Neurosurgery 21:343-346, 1987

44. Mclone D, Naidich T: Terminal myelocystocele. Neurosurgery 16:35-41, 1985

45. McLone D, Thompson D: Lipomas of the spine, in McLone D (ed): Pediatric Neurosurgery. Philadelphia: WB Saunders, 2001, pp 289-301

46. McLone DG, Naidich TP: Laser resection of fifty spinal lipomas. Neurosurgery 18:611-615, 1986

47. Muraszko K, Youkilis A: Intramedullary spinal tumors of disordered embryogenesis. J Neurooncol 47:271-281, 2000

48. Naim Ur R, Salih MA, Jamjoom AH, et al: Congenital intramedullary lipoma of the dorsocervical spinal cord with intracranial extension: case report. Neurosurgery 34:1081-1084, 1994

49. Oakes W: Management of spinal cord lipomas and lipomyelomeningoceles, in Wilkins RH, Rengachary SS (eds): Neurosurgery Update II. New York: McGraw-Hill, 1991, Vol 3, pp 3497-3504

50. O'Neill OR, Piatt JH Jr, Mitchell P, et al: Agenesis and dysgenesis of the sacrum: neurosurgical implications. Pediatr Neurosurg 22:20-28, 1995

51. Pang D: Sacral agenesis and caudal spinal cord malformations. Neurosurgery 32:755-778, 1993

52. Pang D, Wilberger JE Jr: Tethered cord syndrome in adults. J Neurosurg 57:32-47, 1982

53. Patwardhan V, Patanakar T, Armao D, et al: MR imaging findings of intramedullary lipomas. AJR 174:1792-1793, 2000

54. Peter JC: Occult dysraphism of the spine. A retrospective analysis of 88 operative cases, 1979-1989. S Afr Med J 81: 351-354, 1992

55. Pierre-Kahn A, Lacombe J, Pichon J, et al: Intraspinal lipomas with spina bifida. Prognosis and treatment in 73 cases. J Neurosurg 65:756-761, 1986
56. Pierre-Kahn A, Zerah M, Renier D, et al: Congenital lumbosacral lipomas. Childs Nerv Syst 13:298-335, 1997

57. Rappaport ZH, Tadmor R, Brand N: Spinal intradural lipoma with intracranial extension. Childs Brain 9:411-418, 1982

58. Rubin G, Gornish M, Sandbank J, et al: Spinal extradural angiolipoma. Case report and review of the literature. Spine 17: 719-724, 1992

59. Satar N, Bauer SB, Scott RM, et al: Late effects of early surgery on lipoma and lipomeningocele in children less than 1 year old J Urol 157:1434-1437, 1997

60. Satar N, Bauer SB, Shefner J, et al: The effects of delayed diagnosis and treatment in patients with an occult spinal dysraphism. J Urol 154:754-758, 1995

61. Sato S, Shirane R, Yoshimoto T: Evaluation of tethered cord syndrome associated with anorectal malformations. Neurosurgery 32:1025-1028, 1993

62. Scatliff JH, Kendall BE, Kingsley DP, et al: Closed spinal dysraphism: analysis of clinical, radiological, and surgical findings in 104 consecutive patients. AJR 152:1049-1057, 1989

63. Schneider S, Rosenthal A, Greenberg B: A preliminary report on the use of laser-Doppler flowmetry during tethered spinal cord release. Neurosurgery 32:214-217, 1993

64. Shian WJ, Chi CS, Wong TT: Lipomyelomeningocele: a 9-year review. Chung Hua Min Kuo Hsiao Erh Ko I Hsueh Hui Tsa Chih 35:57-62, 1994

65. Shinomiya K, Fuchioka M, Matsuoka T, et al: Intraoperative monitoring for tethered spinal cord syndrome. Spine 16: 1290-1294, 1991

66. Souweidane MM, Drake JM: Retethering of sectioned fibrolipomatous filum terminales: report of two cases. Neurosurgery 42:1390-1393, 1998

67. Towfighi J, Housman C: Spinal cord abnormalities in caudal regression syndrome. Acta Neuropathol 81:458-466, 1991

68. Van Calenbergh F, Vanvolsem S, Verpoorten C, et al: Results after surgery for lumbosacral lipoma: the significance of early and late worsening. Childs Nerv Syst 15:439-443, 1999

69. Warder DE, Oakes WJ: Tethered cord syndrome and the conus in a normal position. Neurosurgery 33:374-378, 1993

70. Warder DE, Oakes WJ: Tethered cord syndrome: the low-lying and normally positioned conus. Neurosurgery 34:597-600, 1994

71. Wood BP, Harwood-Nash DC, Berger P, et al: Intradural spinal lipoma of the cervical cord. AJR 145:174-176, 1985

72. Wu HY, Kogan BA, Baskin LS, et al: Long-term benefits of early neurosurgery for lipomyelomeningocele. J Urol 160: 511-514, 1998

73. Xenos C, Sgouros S, Walsh R, et al: Spinal lipomas in children. Pediatr Neurosurg 32:295-307, 2000

74. Yamada S, Iacono R, Yamada B: Pathophysiology of the tethered spinal cord, in Yamada S (ed): Tethered Cord Syndrome. Park Ridge, IL: American Association of Neurological Surgeons, 1996, pp 29-45

75. Yamashita K, Fuji T, Nakai T, et al: Extradural spinal angiolipoma: report of a case studied with MRI. Surg Neurol 39: 49-52, 1993

76. Yamashita K, Yonekawa Y, Kawano T, et al: High cervical intradural lipoma - case report. Neurol Med Chir 32:285-288, 1992

77. Zide B, Constantini S, Epstein FJ: Prevention of recurrent tethered spinal cord. Pediatr Neurosurg 22:111-114, 1995

Manuscript received December 4, 2000.

Accepted in final form December 21, 2000.

Address reprint requests to: Jeffrey P. Blount M.D., Childrens Hospital of Alabama, ACC 400, 1600 7th Avenue South, Birmingham, Alabama 35233. email: jeffrey.blount@ccc.uab.edu. 